\title{
Ramsar Wetlands: Understanding Change in Ecological Character
}

\author{
Peter Gell1' O. Burge ${ }^{2}$ and R. Flower ${ }^{3}$ \\ Queenscliff, Australia, 6-8 November 2013
}

To ensure protection and "wise use", many wetlands are included in the Ramsar Convention's List of Wetlands of International Importance (www.ramsar.org). Many of these wetlands are under increasing pressure from (i) (hydro-)climate change; and (ii) the direct impacts of people, notably through hydrological modification (decreasing water quantity/quality), land use change, and the proliferation of invasive species.

Listing a wetland requires a site description and account of the "natural ecological character". The site description, undertaken at the time of listing, constitutes a modern baseline against which a wetland's present condition can be measured. However, evidence from the past often reveals a wider range of "natural" conditions, and can inform the potential trajectory (or trajectories) of change through which the wetland is currently passing. This PAGES workshop provided a valuable opportunity for contemporary and paleo-ecologists to review the knowledge of wetland change needed to better manage wetlands of international significance.
Emerging from the 2010 PAGES Floodplain Lakes meeting in Arkansas, USA (Gell et al. 2011) this workshop focused on the nature of wetland change and variability at key Ramsar sites across the globe. It was a true coming together of disciplines demonstrated by the range of conveners, including paleolimnologists - Peter Gell (Focus 4 Water theme leader), Jessica Reeves (OZIntimate leader) and John Dearing (former Focus 4 leader) and neolimnologists - Max Finlayson (Ramsar Scientific and Technical Review Panel), Jenny Davis (Society of Wetland Scientists) and Nick Davidson (Deputy Secretary General, Ramsar). Staged in historic Queenscliff, on the edge of the Bellarine Ramsar site near Melbourne, the workshop attracted over 70 delegates from 10 countries.

The presentations highlighted the substantial pressures on modern wetlands driving the loss of some sites and compromising the ecological character of others. While many recent changes have been anthropogenic in cause, paleorecords demonstrate that adverse changes may have their origins deeper in time than generally realized; that
A
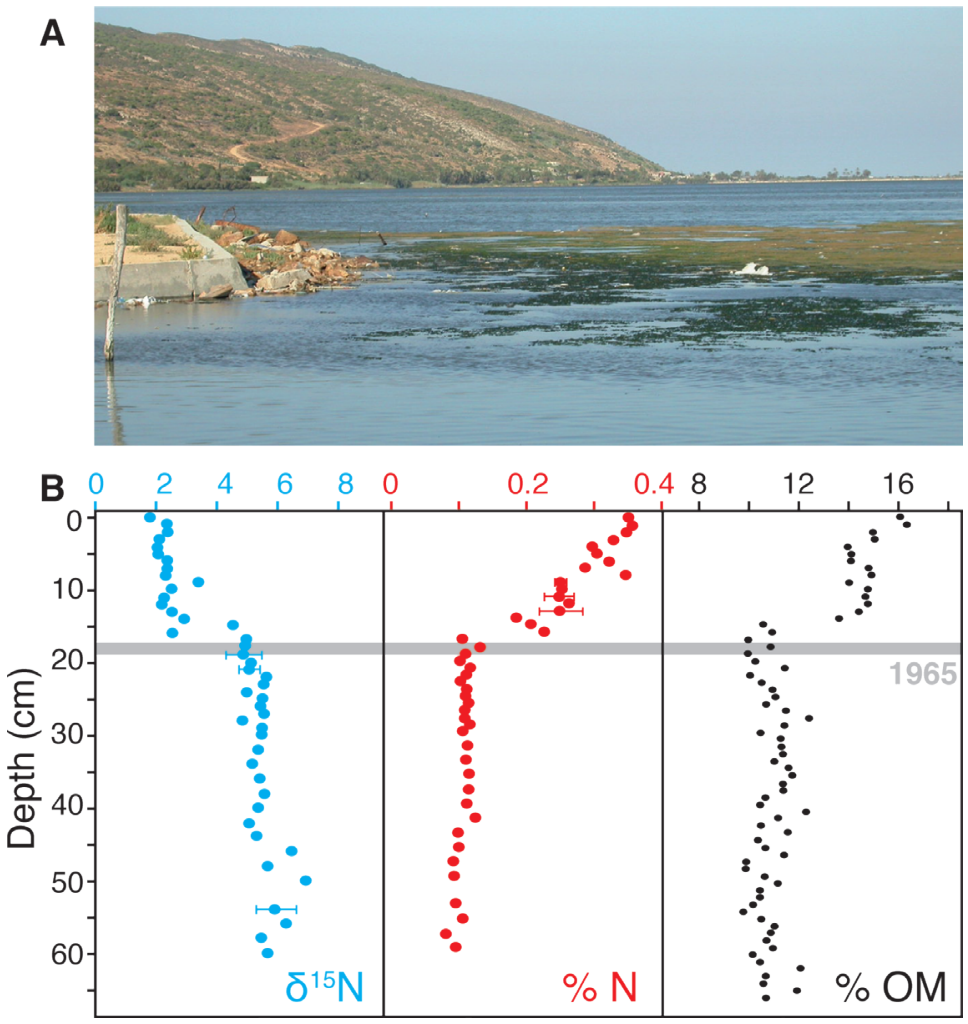

Figure 1: (A) Recent eutrophication of the coastal lagoon of Ghar El Melh (Tunisia) is currently manifested by development of green filamentous algal mats and excessive growth of Ulva rigida. (B) Sedimentary profiles for $\delta^{15} \mathrm{~N}$, percentage nitrogen and percentage organic matter in a dated sediment core from this lagoon indicate marked environmental changes occurred during the 1960s following the introduction of agro-chemical methods and artificial fertilizers (from Oczkowski et al. 2011). natural and induced change can be of a non-linear nature, and that the past "natural" character of a wetland can be surprisingly different from the currently perceived state. With respect to wetland management, it was contended that unanticipated natural features of the past - such as forested wetlands lost at a time in history that exceeds living memory - should be considered suitable options as "restoration" goals for degraded sites. Importantly in places where there has been little investment in wetland monitoring, the paleorecord provides the sole means of understanding the nature of past changes (an example is given in Fig 1).

The meeting had deliberate aims with respect to global wetland management. A high priority Ramsar task for 2013-2015 is to report on "Detecting, reporting and responding to change in ecological charac ter" (mandated by the 2013 Conference of the Contracting Parties [COP 11; Resolution $X I .17])$, and discussion sessions in the workshop focused on framing a Briefing Note to inform the 2015 COP. Clearer understanding of the nature and drivers of environmental change is expected to provide more efficient pathways by which signatory nations may deal with changing conditions which affect their listed wetlands. As recognized at the workshop, understanding these conditions requires parties take account of past, current and future aspects of both global and local-scale forcing of change. The workshop assisted the Ramsar leadership to take steps to enable countries to take such an integrated and comprehensive approach to wetland management.

The workshop was supported by PAGES, the Australian Rural Industries RDC and several Australian NRM agencies, as well as Federation University Australia.

\section{AFFILIATIONS}

${ }^{1}$ Collaborative Research Network, Federation University Australia, Ballarat, Australia;

${ }^{2}$ School of Biological Sciences, University of Canterbury, New Zealand

${ }^{3}$ Environmental Change Research Centre, University College London, UK

\section{CONTACT}

Peter Gell: p.gell@federation.edu.au

\section{REFERENCES}

Birks HH et al. (2001) Aquat Ecol 35: 405-430 Flower RJ et al. (2001) Aquat Ecol 35: 369-388 Gell P et al. (2011) PAGES news 19(1): 36 Gell P et al. (2013) Hydrobiologia 708: 133-144 Oczkowski AJ et al. (2011) Ecol Appl 21:1708-1717 Wang R et al. (2013) Nature 492: 419-422 